\title{
A importância dos compostos intermetálicos de urânio para a Ciência
}

\author{
A.P. GONCALVES, M.ALMEIDA(')
}

$\mathrm{N}$ ESTA COMUNICAÇÃO SERÃO APRESENTADOS sucintamente alguns exemplos de contribuições dadas pelos compostos intermetálicos de urânio para o avanço da Ciência em geral e para o estudo da matéria condensada em particular.

Ao contrário das ligas metálicas, que consistem numa solução sólida desordenada, com um ou mais elementos metálicos, sem composição química particular e muitas das vezes constituídas por misturas de fases, os compostos intermetálicos tem uma fórmula química bem determinada e são constituídos por dois ou mais elementos metálicos que ocupam posições cristalográficas distintas e bem definidas. Entre a grande família dos compostos intermetálicos existe um interesse especial no estudo dos compostos de urânio como se irá mostrar

Uma primeira observação da Tabela Periódica podia levar a pensar que os actinídeos se comportam de maneira semelhante aos lantanídeos. Contudo, o comportamento duma propriedade tão simples como o volume molar, mostra que esta grandeza no caso dos metais de transição tem uma variação aproximadamente parabólica com o número atómico, reflectindo a contribuição dos electrões $d$ para a ligação química, enquanto que nos lantanídeos se mantém aproximadamente constante, devido à não participação dos electrões $4 f$ nas ligações. Já nos actinídeos esta variação é intermédia entre os dois casos anteriores, sendo parabólica para os actinídeos leves e tomando um valor aproximadamente constante para maiores números atómicos. Esta natureza intermédia é devida à maior extensão das orbitais $5 f$, quando comparadas com as orbitais $4 f$, o que permite a participação dos electrões $5 f$ nas ligações químicas dos actinídeos leves e cria uma enorme riqueza de comportamentos químicos e físicos dos seus compostos.

Uma contribuição importante dos compostos intermetálicos de urânio para o estudo da matéria condensada em geral e para a cristaloquímica em particular, deriva do grande número de estruturas tipo com urânio. A classificação estrutural dos compostos intermetálicos, é importante para uma futura previsão e "desenho" de compostos com propriedades predeterminadas, mas requer a existência de estudos cristaloquímicos aprofundados. 0 estudo sistemático de novas estruturas leva à descoberta de novos tipos de vizinhanças atómicas e ao estabelecimento de relações estrutura-propriedades, que tem já permitido a previsão e a síntese de novos compostos intermetálicos

Além de existirem muitas estruturas tipo inicialmente identificadas em compostos com urânio, em geral com elevado numero de coordenação por elementos mais leves, este elemento ocorre também num grande número de outros tipos de estuturas descritas inicialmente com outros elementos. Como exemplo, pode-se referir que apenas com a estrutura tipo $\mathrm{Fe}_{2} \mathrm{P}$ ( $\mathrm{ZrNiAl}$ ) são conhecidas duas dezenas de compostos intermetá- licos de urânio. O estudo sistemático das propriedades cristalográficas e físicas de compostos intermetálicos isoestruturais conduz também ao estabelecimento de novas relações estrutura-propriedades.

Um primeiro resultado da tentativa de estabelecer uma correlação entre as estruturas e as propriedades físicas de compostos intermetálicos de urânio foi o diagrama de Hill para compostos binários. Assim, Hill verificou que, em geral, o aparecimento de ordem magnética em compostos binários de urânio dependia fundamentalmente da distância urânio-urânio. O aparecimento de comportamento antiferro ou ferromagnético praticamente só ocorria para distâncias $U-U$ acima de $3.5 \pm 0.1 \AA$, enquanto que abaixo deste valor os compostos eram normalmente paramagnéticos. Este tipo de comportamento foi depois explicado como devido à sobreposição das orbitais $5 f$, favorecida abaixo do limite de Hill, que não permite o carácter localizado dos electrões $5 f$ e, consequentemente, dificulta o establecimento da ordem magnética. Contudo, o aparecimento de um número cada vez maior de excepções, principalmente em compostos intermetálicos ternários, levou a que se tivessem de considerar outro tipo de interacções para além da sobreposição directa $5 f-5 f$, nomeadamente a hibridação entre as orbitais $5 f$ dos átomos de urânio e as orbitais $d$ ou $p$ dos seus vizinhos próximos

O estudo de compostos intermetálicos de urânio também levou à descoberta 
de novos comportamentos físicos. Referem-se de seguida, a título de exemplo, três casos de compostos ou famílias de compostos de urânio com comportamentos físicos particularmente interessantes.

O composto $\mathrm{UFe}_{4} \mathrm{Al}_{8}$, de estrutura cristalográfica tetragonal, apresenta um comportamento ferromagnético abaixo da temperatura de $150 \mathrm{~K}$ com uma estrutura magnética complexa. A sua estrutura magnética, determinada por difracçâo de neutrões, revelou que os momentos magnéticos dos átomos de urânio e de ferro não estão alinhados paralelamente, mas sim aproximadamente perpendiculares, com os do urânio orientados ferromagneticamente segundo o eixo cristalográfico $a$ (ou b) e os de ferro ordenados quase antiferromagneticamente segundo $b$ (ou $a$ ), mas com um pequeno ângulo que os faz contribuir também para o ferromagnetismo. Um estudo pormenorizado das propriedades magnéticas, de transporte eléctrico e de espectroscopia de Mössbauer em monocristais deste composto mostrou que, em consequência das interacções magnéticas complexas, existe uma grande anisotropia magnética não só entre as direç̧ões $a$ e $c$, mas também no plano $a-b$. Esta anisotropia a baixa temperatura provoca, quando da aplicação de um campo magnético, um comportamento inédito dos domínios magnéticos que ficam bloqueados num estado metaestável intermédio, orientados perpendicularmente ao campo aplicado, geometria esta que, a priori, seria uma das menos favoráveis energeticamente. $O$ estudo das estruturas e do comportamento magnético neste tipo de compostos permite o desenvolvimento de modelos teóricos das interacções magnéticas e o avanço da compreensão de novos materiais como supermagnetes.

Outro exemplo de comportamento das propriedades físicas menos comum e relevante em estudos de matéria condensada é dado pelos sistemas ditos fermião pesado, em que os electrões de condução apresentam massas efectivas várias ordens de grandeza superior não só à dos electrões livres como mesmo à dos electrões nos sistemas metálicos habituais. Este comportamento deve-se à contribuição dos electrões $5 \mathrm{fem}$ bandas relativamente estreitas que podem dar origem a um grande pico na densidade de estados electrónicos junto ao nível de Fermi. Esta grande densidade de estados provoca um enorme aumento do coeficiente linear do calor específico, e os electrões comportam-se como se a sua massa tivesse um valor entre 10 e 100 vezes superior ao dos metais simples. Além deste tipo de comportamento, existem sistemas de fermiões pesados com ordem antiferromagnética e com fases supercondutoras a baixa temperatura, o que tem atraído imenso interesse pelo estudo destes sistemas. Dos seis sistemas de fermiões pesados que apresentam superconductividade a baixas temperaturas cinco são compostos de urânio e destes, quatro apresentam a rara coexistência entre supercondutividade e antiferromagnetismo. 0 estudo deste tipo de compostos tem produzido importantes avanços na compreensão da superconductividade e do magnetismo.

Por último, como exemplo também muito interessante, refere-se o composto intermetálico de $\mathrm{UGe}_{2}$ recentemente reportado como um ferromagnete itinerante abaixo da temperatura de $52 \mathrm{~K}$ mas que se pode transformar num superconductor, desde que seja aplicada uma pressão acima de 1.0 GPa. Embora seja um trabalho muito recente, a descoberta deste fenómeno abre enormes perspectivas para o estudo da superconditividade e da sua relação com o magnetismo

\section{O Urânio em Fase Gasosa}

$\mathrm{E}$ M FASE CONDENSADA, SEJa EM SOluÇão ou no estado sólido, os processos químicos são claramente influenciados pelo meio denso formado pelo solvente ou pela rede. Em fase gasosa, em particular num sistema funcionando a baixas pressões como um espectrómetro de massa, podem estudar-se as propriedades quimicas intrínsecas de espécies iónicas na ausência de factores de perturbação devidos ao meio.

No Departamento de Química do ITN temos vindo a utilizar a espectrometria de massa para estudar a reactividade em fase gasosa de iões das séries dos lantanídeos e dos actinídeos com diferentes moléculas orgânicas, examinando os mecanismos, a cinética e a energética das reacções. O objectivo tem sido tentar compreender os padrões de reactividade dos iões metálicos do bloco fatravés da sua relação com as estruturas electrónicas dos iões. Simultanea- 